\title{
Cultura escolar, móviles y fotografía digital
}

\author{
School culture, smartphones and digital photography
}

Culture scolaire, téléphones intelligents et photographie digitale

\author{
José C. Lisón Arcal \\ EMUI (Euro-Mediterranean University Institute) \\ Universidad Complutense de Madrid
}

\section{RESUMEN}

La cultura analógica prevalece en las escuelas de la era digital, lo que se traduce en una dificultad del modelo de educación formal reglada para proporcionar a los alumnos los conocimientos y saberes prácticos necesarios para adaptarse con éxito al mundo que les toca vivir. Tomando como referencia las recomendaciones de la NCTE para reorientar el modelo educativo y cubrir esas carencias, se analiza cómo el uso que los más jóvenes hacen de los smartphones contribuye en buena medida a paliar esta deficiencia. Mediante la integración de este dispositivo en las aulas y dando más peso al uso de la fotografía digital en el proceso de aprendizaje se podría dar una respuesta inmediata y factible a esta situación de desfase.

Palabras clave: cultura escolar, pensamiento analógico, pensamiento digital, pensamiento complejo, aprendizaje, smartphones, fotografía digital.

\section{ABSTRACT}

The analog culture prevails in the school of the digital age, resulting in an inadequacy of the model of formal education to provide students with the knowledge and practical skills needed to successfully adapt to the world in which they live. Taking as reference the recommendations of the NCTE to reorient the educational model and cover these gaps, it is discussed here how the use younger people make of smartphones contributes largely to alleviate this deficiency. By integrating this device in classrooms and giving more weight to the use of digital photography in the learning process, you could give an immediate and feasible response to this situation lag.

Keywords: school culture, analogical thinking, digital thinking, complex thinking, learning, smartphones, digital photography. 


\section{RÉSUMÉ}

Une culture analogue prévaut dans les écoles de l'âge digital, ce qui résulte en une insuffisance du modèle d'éducation formelle à fournir aux étudiants les connaissances et les habiletés nécessaires pour s'adapter avec succès au monde dans lequel ils vivent. En nous appuyant sur les recommandations du CNTE pour réorienter le modèle éducatif et combler ces lacunes, nous soutenons que la manière dont les plus jeunes utilisent le smartphone contribue à atténuer cette déficience. En intégrant cet appareil dans nos salles de classe et en donnant plus de poids à l'usage de la photographie digitale dans le processus d'apprentissage, vous pouvez donner une réponse immédiate et réalisable à cette situation de décalage.

Mots-clés: culture scolaire, pensée analogique, pensée digitale, pensée complexe, apprentissage, smartphones, photographie digitale.

\section{Entre analógicos y digitales}

La digitalización todavía está entrando en la cultura escolar de manera difusa y a trompicones por más que los ordenadores, los videoproyectores y las pizarras digitales hayan hecho acto de presencia y se hayan convertido en parte de la parafernalia habitual que acompaña la actividad docente. La introducción de estos aparatos y, por ende, de la tecnología con la que están pensados y construidos, no significa que el pensamiento digital se haya impuesto en la cultura escolar. Entiéndase por cultura escolar todo ese conjunto de formas establecidas de hacer, pensar, sentir y organizar el proceso estructurado de aprendizaje establecido en el mundo de la educación formal y reglada. Hablamos por tanto de un conjunto de normas sostenidas por valores, símbolos y significados compartidos que interiorizan tanto docentes como estudiantes, construyendo y ordenando así el entramado en el que se insertan las instituciones dedicadas a la adquisición de conocimientos socialmente reconocidos. Como señala Morin (1994, pp. 75): “Una cultura abre y cierra las potencialidades bioantropológicas del conocimiento". Por un lado nos proporciona sus saberes y conocimientos acumulados y por otro nos limita con sus normas, prohibiciones, su etnocentrismo y "su ignorancia de su ignorancia". Una cultura escolar de la era analógica difícilmente puede tener vigencia ni tampoco es apropiada ni adecuada en una época digital.

La finalidad de este acotamiento inicial que puede parecer un tanto reduccionista no es otra que centrar el foco de atención en los patrones, valores y actitudes que habitualmente suelen guiar el aprendizaje en la escuela. Sin duda, no hay un único modelo ni pretendo concentrarme exclusivamente en lo que podría denominarse la escuela tradicional. Hay diferentes modelos y métodos de aprendizaje que se han desarrollado con la intención de romper con los moldes considerados tradicionales o más comúnmente 
establecidos en la enseñanza reglada. Responden a un intento de superar limitaciones percibidas, mejorar resultados y disminuir el fracaso escolar a la par que hacer más feliz o menos traumática la experiencia del aprendizaje (p.e.: Giordan, 1995; García-Pérez, 2000; Monereo (coord.) 2001; Joyce, Weil, \& Calhoum, 2002; González-Peiteado, 2013). Aun así, el planteamiento que pretendo hacer aquí no deja de compartir con todos ellos, creo, algunos interrogantes, problemas y reflexiones sobre cómo abordar con una mirada diferente ciertas contradicciones propias de las situaciones de cambio, fundamentalmente cultural y tecnológico, que se viven en la escuela actual.

El título de este ensayo incluye la fotografía digital como elemento importante de la reflexión que intento realizar. El calificativo digital no es menos relevante que el sustantivo como veremos a continuación. Desde su aparición, la fotografía en la escuela no ha ido mucho más allá que servir para documentar someramente la actividad de esta institución. Me vienen a la mente las fotos de todos conocidas por haber posado para ellas, fotografías de grupo, que se siguen haciendo en la actualidad (con tecnología digital pero con pensamiento analógico) y que, entre otras cosas, reflejan el tránsito de las personas por la institución educativa. También están las individuales, y unas y otras tienen ese valor de guardar para la memoria el pequeño rito de paso que supone crecer en edad y reconocimiento social, a medida que se superan etapas regidas por pruebas cuidadosamente ritualizadas y marcadas en el tiempo. Cada curso aprobado es un escalón ascendido camino del reconocimiento de la condición de adulto. Un paso más acumulando conocimientos, un capital simbólico que supuestamente contribuirá a una integración exitosa en la sociedad. Nada más adecuado que la fotografía para dejar constancia de este rito de paso. Sobre el sentido de estas fotografías analógicas reflexiona Velasco en una interesante revisión y análisis sobre su construcción y valor institucional y social (Velasco, 2011, pp. 15-34). Pero, más allá de esto, me parece oportuno resaltar que estas instantáneas reflejan una forma de pensar y entender la fotografía que perdura en el ámbito escolar y que tiene que ver con una forma analógica de organizar el aprendizaje, desaprovechando las nuevas perspectivas que nos abre la digitalización.

Sin embargo, la fotografía, al digitalizarse, ha adquirido una nueva dimensión y ha abierto nuevas posibilidades de recogida y acumulación de información, de análisis de datos, de representación y construcción de conocimiento. No es sólo que en la cultura digital predomine lo multimedia frente a lo escrito y oral, sino que ahora la facilidad y escaso coste de hacer fotos, almacenarlas y recuperarlas de inmediato en la pantalla de cualquier dispositivo portátil como el móvil, las pone al alcance de casi cualquier persona. Pero también casi cualquiera puede retocarlas y editarlas, enviarlas y recibirlas integradas en cualquier intercambio de información. Más aún, la inmediatez de su factura, la disponibilidad, y la capacidad de integrar en una instantánea múltiples niveles de información, entre otras cosas, la han convertido en una poderosa herramienta, imprescindible también en el contexto del aprendizaje y de la investigación. Es desde esta 
perspectiva desde la que pretendo abordar aquí su vigencia, valor y eficacia en el contexto de la escuela de la era digital.

\section{El papel del texto}

El aprendizaje en la escuela se ha fundamentado tradicionalmente en el uso de textos analógicos, o como dice González Alcantud (1999, pp. 52) en el "grafocentrismo", con la ocasional compañía de alguna foto analógica a modo de ilustración secundaria. Una de las características más reconocibles tanto de las fotografías como de los textos analógicos es su condición de documentos impresos y como tales únicos, definitivos, inamovibles, capaces de perdurar sin cambios durante toda su existencia. Los textos y fotos sobre papel se piensan, se construyen, se organizan, se redactan y se enfocan sobre esa base. Aquello sobre lo que tratan debe quedar explicado con la suficiente claridad y precisión como para no necesitar, al menos en principio, de ulteriores explicaciones o modificaciones. Una vez impresos, el texto y la foto instantánea quedan fijados totalmente y cualquier error u omisión pasará a formar parte de su propia condición. Con la impresión en papel la decisión está tomada y no hay vuelta atrás, algo que también contribuye a dotar de no poca autoridad a la fotografía y al texto analógicos. No en vano los pactos y contratos se detallan y firman por escrito en un intento de trascender el tiempo, resistir el olvido y preservar fielmente el espíritu de lo acordado. Lo mismo sucede con esas fotografías en papel (con frecuencia enmarcadas) de los ritos de paso de nuestras vidas que tratan de inmortalizar y dar fe de nuestro tránsito por ellos. Es una cualidad de las fotos y textos analógicos impresos el que, siendo documentos únicos, han de imprimirse de uno en uno y cada cual es una nueva unidad independiente y tan única y definitiva como cualquiera de ellas. Son documentos gráficos materializados, fijos, incómodos para observar, leer y trabajar en equipo, algo que no sucede con los digitales e hipertextos.

Esos documentos analógicos, en especial los textos, han gozado y todavía gozan de una autoridad propia del conocimiento socialmente aceptado como válido y vigente. No en vano han sido el soporte principal de la construcción, transmisión y preservación de ese conocimiento. Eso supone inevitablemente un condicionamiento que ha marcado nuestra forma no sólo de aprender, transmitir y preservar, sino también de conceptualizar, entender y dar sentido al mundo. La palabra, hablada o escrita, el "logocentrismo" y el "grafocentrismo", han sido tradicionalmente, y en buena medida siguen siendo, los medios habituales en los procesos formales de construcción y adquisición de conocimiento. El dominio de la palabra ha contribuido decisivamente a otorgar a profesores y maestros autoridad, pues es un signo que se resuelve en lo que significa y para entenderla hay que poseer un dominio de la lengua, mientras que otros códigos, como la imagen, permiten más libertad de interpretación, restando autoridad al emisor (Sartori, 1998, pp. 35). Ahí reside en parte el miedo de autores como Sartori (o. c.) y Rozak (2006) ante el mayor peso adquirido por las imágenes en la cultura digital. Ambos nos advierten en sus obras sobre el 
deterioro de la capacidad de pensar profundamente que conllevaría el predominio de lo multimedia.

El principio de autoridad analógico presenta cada vez más fisuras en un mundo digitalizado en el que la construcción, comunicación y difusión de información y conocimiento no sólo se apoya en el uso masivo de imágenes digitales sino también en el "intercambio generalizado de saberes" (Lévy, 2007, pp. 145-147). Los procesos de formación y aprendizaje estrictamente institucionalizados pierden fuerza ante una situación de disponibilidad abierta de los conocimientos y de la capacidad de autoformación que ofrecen las nuevas tecnologías. La estratificación basada en el acceso diferencial a los recursos del conocimiento se difumina y reorganiza. El aprendizaje cooperativo y la creación colectiva cobran cada día más importancia y se imponen en nuestras vidas, desbordando el control institucional y sus modelos organizacionales analógicos. La vieja idea de que los saberes adquiridos en la escuela eran estables y duraderos, válidos de por vida, se desmorona. En el mundo analógico, el conocimiento está asociado a la presencia material de las fotos y de los textos impresos que ha contribuido a dotar de un sentido de continuidad, estabilidad y seguridad al conocimiento así representado. El curso de la vida se presentaba marcado por la linealidad, al igual que la lectura de un texto impreso que está concebido para que así se entienda, para acceder de manera dirigida a sus significados perdurables. Con los hipervínculos se pasa a saltar directa e inmediatamente a cualquier dato disponible, se puede elegir el camino a seguir e incluso optar por añadir información, una información que ya no se acumula de manera limitada en el tiempo y el espacio ni se genera de manera unidireccional (Lisón, 2011, pp. 35-52).

El pensamiento digital se asienta sobre bases y fundamentos lógicos diferentes y por tanto construye y configura el conocimiento de manera distinta al modelo analógico tradicional de la escuela (Dussel \& Quevedo, 2010; Dussel, 2011). Buena parte de los valores propios de un entorno analógico como sus principios de autoridad y autoría, de unicidad, de continuidad y permanencia, todavía tienen un peso importante en la cultura escolar. A ellos se suman algunas de sus limitaciones, como la escasa flexibilidad, la menor capacidad de acumulación, almacenamiento y análisis de datos, el coste elevado de la reproducción, la falta de interactividad e inmediatez y la poca cabida a la innovación y la cooperación para la que resulta un impedimento la propia condición física del material impreso. El soporte digital, por el contrario, favorece la implicación del usuario-actor en cualquier proceso de comunicación y aprendizaje, permitiendo niveles muy elevados de interactividad y autonomía.

Retomando la importancia de la imagen, fija y en movimiento, en los procesos de construcción y representación de la información y el conocimiento en la cultura digital, hay que reconocer que en la escuela siempre ha habido imágenes analógicas con las que ha pretendido apoyar el proceso de aprendizaje. Ahí tenemos esos mapas tan presentes en las aulas del pasado, inmortalizados por la frecuencia con que fueron utilizados como fondo de 
las fotografías escolares, muestra de los recursos valiosos y "modernos" que contribuían a ampliar la concepción del espacio geográfico. También los libros fueron introduciendo, a medida que la tecnología de la imprenta avanzaba, más y más gráficos, ilustraciones y fotografías. Hoy, cualquier texto escolar que se precie ha de exhibir un estudiado despliegue de imágenes y colorido que no es sino mera comparsa que acompaña al texto, pues la imagen casi siempre ha tenido y en parte sigue teniendo un carácter secundario, de refuerzo, ilustrativo, incluso se usa todavía como un valor lúdico que suaviza y aligera la dureza de la lógica abstracta del texto, facilitando el proceso fundamental. Esta prevalencia del pensamiento analógico en el uso de las imágenes se evidencia todavía cuando muchos docentes, que no han entendido el sentido digital de un PowerPoint, continúan proyectando diapositivas plenas de texto que leen a la audiencia como si ésta fuera analfabeta, introduciendo en las aulas el karaoke. No han comprendido la capacidad de las imágenes para posibilitar la asimilación inmediata de conceptos complejos, asociándolos con emociones y sentimientos, con una sensación de participación y "copresencia" de "un orden metafísico" (Barthes, 1981), difícilmente posible de otro modo. Aquellos, hacen un uso perverso de las nuevas tecnologías, guiados por pensamientos analógicos, principios de autoridad y sentidos caducados.

\section{V(I+D+i)ojuegos y smartphones}

Como ya he indicado, también existen movimientos que intentan cambiar este modelo analógico y que reconocen que toda metodología de enseñanza impone una forma de concebir el mundo. Algunos abogan por una escuela activa radical en la que el monolitismo de los viejos modos y textos se substituya por la participación activa, fomentada, dinámica e integrada de los alumnos, apoyándose en el uso de herramientas multimedia (Paredes, 2011). Esta postura es coherente con la época del hipertexto y los multimedia digitales (Rodríguez Rodríguez, 1999), con los "nuevos alfabetismos" y formas de textos "postipográficas" (García Vallinas, 2011; Lankshear \& Knobel, 2011) o con las ideas de Steven Johnson, tan rompedor como clarividente en su trabajo "Everything Bad is Good for You," donde argumenta que los medios audiovisuales juegan un importante papel de entrenamiento cognitivo que favorece el pensamiento complejo (Johnson, 2005).

Resulta revelador de los prejuicios existentes sobre los medios audiovisuales digitales el escaso eco que han tenido los hallazgos de algunos experimentos realizados, hace más de un cuarto de siglo, sobre su impacto en los procesos cognitivos. Los resultados contradicen contundentemente los argumentos de quienes auguran un empobrecimiento de la capacidad de pensar. Alguna de las instituciones implicadas en las investigaciones de referencia, como la Universidad de Manchester, difícilmente pueden ser acusadas de estar movidas por intereses ocultos. Esta prestigiosa institución académica realizó, ya en 1989, un estudio que desveló la validez de los videojuegos comerciales para medir el IQ porque exigen del jugador un importante número de habilidades asociadas al pensamiento 
complejo. Muchos videojuegos, por no decir la mayoría de ellos, se basan en sistemas complejos de reglas que exigen reacciones y respuestas rápidas a situaciones imprevistas o no familiares, interactividad, flexibilidad, capacidad de adaptación y competitividad, contribuyendo al desarrollo de estas capacidades asociadas con cualidades del modo de pensar digital. Más aún, como señalaban los autores de este experimento (Rabbitt, Banerji \& Szymanski, 1989, pp. 55), el contexto de juego favorece notablemente la implicación intensa de los participantes, algo que tiende a perderse en los "aburridos" analógicos tests de laboratorio, con lápiz y papel. A pesar de este descubrimiento apenas se ha avanzado en la consideración social de los videojuegos que, para la inmensa mayoría, continúan siendo obstáculos para un aprendizaje adecuado. Como señala Gee (2004), el problema de introducir los videojuegos en las instituciones y procesos educativos no es de coste económico, sino de lo que cuesta cambiar la mentalidad de la gente sobre cómo y dónde se aprende. También es cierto que no todos los videojuegos son idóneos para fomentar un buen proceso de aprendizaje y, en este sentido, también un trabajo de Gee (2008) resulta clarificador de las cualidades de un "buen videojuego" para un "buen aprendizaje", entre las que destacan la identificación e implicación, la agencialidad, saber asumir riesgos y aceptar retos y la interactividad.

Aunque los docentes, para introducir las nuevas tecnologías en las escuelas, han aprendido a manejar pizarras digitales y aplicaciones novedosas, todavía escasean los que crean contenidos multimedia con fines distintos a la recolección y presentación de información. Además, no siempre cuentan con la preparación ni los medios necesarios para adquirir y mantener los equipos como explican Barrantes y Baron (2011) en su análisis de proyectos educativos con nuevas tecnologías en México y Colombia. Con una perspectiva tan limitada del alcance de las posibilidades de las tecnologías digitales no se puede sacar partido a las potenciales ventajas de algunos poderosos medios digitales habitualmente disponibles. Es necesario mirarlos con otros ojos y evitar verlos como obstáculos en el proceso de aprendizaje formal, bien porque se considera que distraen la atención de los alumnos, bien porque les distancia de los deseables hábitos de lectura. Estoy pensando concretamente en ese denostado aparato denominado smartphone que habita en las mochilas y bolsillos de la virtual totalidad de los estudiantes en los países en los que los gadgets de la era digital se han introducido de manera generalizada entre la población.

Tampoco parece que los antropólogos, que se supone deberíamos estar acostumbrados a buscar nuevos significados implícitos en nuestro universo cotidiano, hayamos estado alerta. De hecho, cuando digo a mis estudiantes de técnicas de investigación con medios audiovisuales que llevan a cuestas una herramienta miles de veces más potente que aquel ordenador de más de una tonelada de peso que acompañó a los primeros astronautas que pisaron la luna, muchos se miran sorprendidos. Parece como si descubrieran que su apreciado móvil les oculta algún secreto que todavía no acertaron a descubrir. Si añado que debería ser su herramienta fundamental para el trabajo de campo antropológico, algunos todavía me miran con desconfianza. Al fin y al cabo, ¿a quién se le 
puede ocurrir que un aparato asociado al ocio adquiera de repente un valor tan distinto? Será una broma, porque lo estipulado es que para entrar en clase hay que apagarlo y retirarlo de la vista de los profesores. Y no les faltan motivos para la desconfianza porque todavía abundan los progenitores que retrasan la entrega de un móvil a sus hijos por temor a que les robe el tiempo de estudio y cree nocivas adicciones. Probablemente, parte del problema de ciertas adicciones se paliaría dotando al aparato de un nuevo significado y adjudicándole un papel importante en los procesos de adquisición y construcción del conocimiento en la escuela.

¿Por qué no cambiar de enfoque? ¿Por qué no introducir e integrar el smartphone en los procesos de aprendizaje como una herramienta poderosa, que prácticamente todo el mundo lleva a cuestas y a la que apenas se le saca partido? Andrea Leyden (2015) tiene un post en el blog Examtime titulado "40 usos para smartphone en la escuela". Allí se enumeran un buen puñado de posibilidades que deberían resultar más que evidentes. Tenerlas en cuenta podría, por ejemplo, ahorrar la inversión en tabletas y portátiles de los centros educativos; medios caros y de rápida obsolescencia, un problema relevante para entornos escolares con recursos limitados (Barrantes y Baron, 2011; Area y Sanabria, 2014). De hecho, en Kenia hay una serie de plataformas móviles muy utilizadas como escuelas online. Una de ellas, Eneza, ayuda a distribuir conocimientos a través de móviles básicos, con menor potencia y capacidad que los actuales smartphones. La web de Eneza asume como misión "hacer más listos a 50 millones de niños a través del uso de la ubicua tecnología del móvil" (http://enezaeducation.com/about-us/).

Más aún, en el trabajo de campo antropológico el móvil sirve para más que recoger datos, aunque su eficaz grabadora de voz, su potente cámara fotográfica y su nada despreciable calidad a la hora de grabar video, lo convierten en un aliado fundamental. Pero si pensamos en él como una herramienta profesional, enseguida se nos abren otras posibilidades que resultan de no poca utilidad. Sólo es cuestión de asociar alguno de sus múltiples usos con necesidades particulares, por ejemplo, antes de entrar en el "campo", en el inicial tanteo con quienes queremos que sean nuestros informantes. Yo suelo utilizar una serie de fotos personales como tarjeta de presentación para romper el hielo de los primeros contactos con excelentes resultados. Las fotos muestran una identidad en la que se puede confiar, son una prueba de que tengo familia, amigos, trabajo y lugares de arraigo. Enseñarlas es un indicador de cierta confianza que suele calar positivamente en las personas y abrir puertas. Podría señalar aquí una larga lista de situaciones en las que el móvil o smartphone puede jugar un papel crucial en el quehacer antropológico y cualquier antropólogo podría otras. El primer paso, tanto en la antropología como en la educación, estaría en cambiar la perspectiva asumida sobre algo que tenemos integrado en nuestra cotidianidad para verlo con otros ojos y otras posibilidades. Deberíamos empezar por cambiar de forma de mirar y estar abiertos a pensar en las nuevas tecnologías y sus productos sin las ataduras de lo dado por descontado y, por supuesto, del modo de pensamiento analógico. 
Volvamos a la escuela e intentemos practicar este cambio de perspectiva reflexionando sobre el papel que pueden jugar en el proceso de aprendizaje tanto el smartphone como la fotografía digital. Esta última forma parte inseparable de los principales y más extendidos modos de comunicación utilizados por las personas jóvenes (y no tan jóvenes) en el mundo actual y el móvil es su medio ideal. Con el móvil se toman fotos, se retocan, se suben a las webs desde donde se comparten o directamente se envían por WhatsApp. Son casi imprescindibles en la comunicación digital y de hecho basta con pensar en el auge del "selfie" y su uso comercial para percibir la importancia de la fotografía. No obstante, integrar el móvil en la cultura escolar no es tarea de un día porque aquel ya cuenta con un rechazo inicial importante y, además, con la limitación de que, en general, los docentes son menos expertos que los alumnos en su manejo. Por otro lado, tanto el rechazo como el conocimiento limitado de la herramienta corresponden mayormente al profesorado y a quienes diseñan los itinerarios curriculares. A pesar de todo, una parte de los docentes suele estar abierta a las innovaciones, aunque con frecuencia no cuenta ni con los recursos ni con el entorno adecuados (Sancho y Hernández, 2004, pp. 46-47; Fletcher, 2006; Kotrlick \& Redmann, 2005; Aguaded Gómez y Tirado Morueta 2008). Bien es cierto que cualquier renovación, o viene del profesorado o difícilmente será posible (Paredes, 2011) y para ello habrá que conseguir que los docentes se liberen de los corsés dictados por los supuestos expertos que les dan los cursillos de formación e introduzcan sus propios criterios basados en su experiencia y en el diálogo con los colegas y alumnos.

\section{Cambio de tercio}

Pensemos por un momento en una serie de valores asociados a la cultura digital y al éxito social, a cualidades demandadas en el mundo actual a los profesionales de prácticamente cualquier especialidad. Hagamos una lista limitada para una reflexión inicial sobre la forma de integrarlos en la cultura escolar. Tomemos como referencia las habilidades propias del nuevo alfabetismo digital mencionadas por el NCTE (US National Council of Teachers of English) en 2007 (citado en Lankshear \& Knobel, 2011, pp. 24-25). A partir de ellas podemos reflexionar también sobre cómo el móvil y la fotografía digital asociada pueden ser medios de canalización muy potentes y adecuados para conseguir tal integración. Estos elementos tienen una ventaja añadida. Están plenamente disponibles y forman parte de la cultura actual. Esto último tiene un valor añadido porque una de las principales premisas para que la introducción de un cambio tenga posibilidades de éxito es la compatibilidad cultural (Cernea 1995; Kottak 1995). Es decir, que pueda ser incorporado con facilidad y sin apenas rechazo en el conjunto de valores, pautas, instituciones o tradiciones ya vigentes. De este modo se evita que choque con ellas y acabe resultando inaceptable.

El NCTE se planteaba ya en 2007 la urgente necesidad de reorientar su modelo educativo para dar respuesta a los cambios impulsados en las prácticas sociales cotidianas 
por los efectos de la economía global, las nuevas tecnologías y el crecimiento exponencial de la información. Para ello recomienda orientar la docencia hacia la solución de problemas, la colaboración y el análisis, así como a adquirir habilidades en el manejo y comprensión del software relacionado con los procesadores de textos, los hipertextos, las webcams, el streaming digital y las redes sociales entre otros. En 2008, esta misma institución (citado en Lankshear \& Knobel, 2011, pp. 24-25) declara que una persona alfabetizada del siglo XXI debe poseer un amplio abanico de habilidades y competencias, conocimientos prácticos o alfabetismos que deben ser "múltiples, dinámicos y maleables". En resumen, se afirma que la gente alfabetizada de hoy y del futuro tiene que saber (a) usar con soltura las nuevas tecnologías, (b) trabajar en equipo incluso con personas de otras culturas, (c) diseñar y compartir información con las comunidades globales, (d) manejar múltiples flujos de información simultánea, (e) crear y analizar textos multimedia y (f) asumir las responsabilidades éticas de un entorno tan complejo. Como señalan Green y Hannon (2007, pp. 24) ninguna de estas habilidades suele formar parte de lo que habitualmente se enseña explícitamente en las escuelas. De hecho, que esto pudiera enseñarse a la vieja usanza, con un profesor plantado frente a una clase, es algo que está por demostrar.

La primera recomendación del NCTE hace referencia a la inexcusable necesidad de poseer una elevada capacidad de utilización de las nuevas tecnologías. Como he señalado arriba, el móvil, que prácticamente todos los estudiantes manejan con soltura y acarrean a todas partes, puede ser un elemento muy adecuado para introducir en la escuela este tipo de conocimientos prácticos propios de lo que podríamos denominar un alfabetismo digital. Sin embargo, el smartphone, que se considera inapropiado para la escuela, forma parte esencial de las nuevas tecnologías vigentes y en la vida social, cultural, económica y política que transcurre fuera de las aulas es una herramienta fundamental de trabajo y comunicación cuya ausencia resulta poco menos que inconcebible. Se trata de una contradicción que manifiesta el desfase entre la cultura escolar analógica y la "vida real" digital. Más contradictorio todavía es que los más jóvenes suelen ser los usuarios más avanzados, creativos e innovadores de las muy numerosas aplicaciones disponibles. Esta soltura y conocimiento experto se desaprovechan y desprecian en lugar de tratar de canalizarlos e integrarlos en los procesos de aprendizaje y de construcción de conocimiento.

\section{¿Primitiva modernidad?}

En cierto sentido, los usuarios avanzados del smartphone van por delante en laadquisición de los conocimientos prácticos de la alfabetización necesaria para adaptarse al siglo XXI. Sacan más partido a las nuevas tecnologías (porque suelen tener el móvil sincronizado con los restantes dispositivos y con las "nubes"), y están muy abiertos y estimulados para utilizarlas. Lo hacen creativa, flexible y muy ampliamente, colaboran constantemente en el 
proceso de aprender/enseñar nuevas utilidades e incluso en su desarrollo, y todo ello lo hacen de muy buena gana. Es decir, se hallan implicados en un proceso constante de adquisición de conocimientos relacionados con el manejo de información compleja y de cooperación entre pares. La interconexión de los dispositivos móviles favorece el trabajo en equipo y la colaboración, facilita la superación de barreras transculturales y elimina obstáculos porque se cree compartir un código de comunicación que genera un sentido de pertenencia a una comunidad de usuarios con intereses comunes. Todo esto forma parte esencial del alfabetismo digital deseable según la NCTE.

Más aún, en Internet funciona un código informal, pero no menos importante, de lo que en palabras de Rheingold (citado en Lankshear \& Knobel, 2011, pp. 27) es una "reciprocidad difusa". Una especie de solidaridad entre internautas que comparten de manera supuestamente desinteresada información de todo tipo y en cualquier formato, sean programas, música, videos, etc. No importan la raza, nacionalidad, género, creencias o color de piel de los implicados. Se trata de un sistema de acumulación de prestigio muy parecido al de los sistemas políticos no centralizados descritos en la Antropología Política clásica. Se acumula una especie de "capital social" o capacidad para conseguir la participación de otros en la consecución de una meta o proyecto (Rheingold, o.c.). Se construye una reputación a base de aportar cantidades importantes de conocimientos o archivos deseables para descargar y compartir y que implica dedicar muchas horas de trabajo, en principio, no remunerado. La influencia así acumulada no es permanente, sólo se sostiene si se continúa alimentando a base de una dedicación y un esfuerzo persistentes cuyo resultado se suele medir en términos de visitas, descargas, aportes, etc. Me recuerda la "sociedad indivisa" (Clastres, 1981, pp. 12), en la que para conseguir reputación, prestigio e influencia hay que estar en constante deuda con el grupo "y el poder no está separado de la sociedad". Una deuda impagable porque el grupo siempre espera más y bajar el ritmo de aportaciones resta capital y reconocimiento. Así se frena la aparición de reguladores con capacidad de imponer su criterio sobre el conjunto social. Los ecos del "big man" del Pacífico Sur son demasiado fuertes para no mencionarlo, así como los liderazgos sin capacidad coercitiva descritos por la Antropología política (Pospisil, 1963; Chagnon, 1968; Lee, 1979; Silberbauer, 1983; Fortes \& Evans-Pritchard, 1979; Lowie 1979). Antaño considerados "primitivos", ahora florecen como modelo de funcionamiento de las redes sociales digitales. Encajan bien con la sociedad red de Castells (2000), cuya estructura social es un sistema dinámico y abierto, capaz de soportar constantes inputs de innovación sin desequilibrarse. Para hacerlo posible tienen que deshacerse del modelo centralizado de poder analógico y operar de manera descentralizada, elástica y adaptable. Se trata de sistemas de regulación con principios muy flexibles que, si antaño se pensaban más apropiados para sociedades de un número reducido de miembros, hoy se imponen y funcionan eficazmente en la gestión de la masiva actividad en Internet.

El viejo principio de autoridad centralizada de la escuela analógica choca con el principio de liderazgo digital. Aquí el smartphone también juega un papel importante 
porque es el medio más usado para conectarse a internet desde cualquier punto y participar de cualquiera de las comunidades virtuales, y hacerse presente en las redes sociales más frecuentemente utilizadas. En realidad, gracias a los móviles los más jóvenes pueden formar grupos con gran facilidad, para cualquier fin y plazo y sin las cortapisas de ninguna institución formal. Desde esos grupos, son capaces de participar de inmediato en actividades sociales, políticas, culturales de manera amplia y eficiente (Gee, 2010, pp. 165193), cambiando la naturaleza de las formaciones sociales y el poder. ¿Qué sentido tiene desaprovechar todas estas capacidades y potencialidades disponibles?

Castells (2000, pp. 96-97), hablando sobre los actores y centros de la revolución tecnológica en Sillicon Valley, señala la importancia de los intercambios constantes de cerebros de unos proyectos a otros. Una práctica de fertilización cruzada en la que jugaron un gran papel las permanentes tertulias nocturnas en un bar de la zona: "Estas tertulias hicieron más por la difusión de la innovación tecnológica que la mayoría de los seminarios de Stanford". Una vez más, los entornos de ocio, distendidos, informales, cooperativos, entre iguales, abiertos a la participación, aparecen como la clave del desarrollo de pensamientos complejos potencialmente exitosos. Tan es así que las empresas tecnológicas han apostado por reproducir estos entornos en sus espacios de trabajo, imponiendo el "modelo campus" que ofrece todo tipo de servicios y estímulos para mejorar el rendimiento.

\section{Mi móvil en mi escuela/ mi escuela en mi móvil}

Hasta ahora, como podemos ver, sin siquiera entrar en la escuela, el móvil está cumpliendo en buena medida con el papel de facilitador de la adquisición de esos conocimientos prácticos considerados imprescindibles para el ciudadano alfabetizado del siglo XXI. Más aún, los usuarios avanzados del smartphone suelen estar a la altura de otra de las exigencias de la NCTE: manejar flujos múltiples de información simultánea. Bien es cierto que no todos desarrollan la misma capacidad de hacerlo pero el uso que los más jóvenes (también los no tan jóvenes) hacen del móvil implica un mínimo de habilidad en este sentido. Volviendo a Rheingold, esta capacidad multitarea, criticada desde el estamento escolar y académico, consiste fundamentalmente en lo que él denomina "muestreo de flujos," la capacidad de seleccionar sobre la marcha lo relevante de cada flujo y descartar el resto. Se trata de aprender otra forma compleja de prestar atención que implica reconocer qué vale la pena en términos de calidad, relevancia y otras variables. Así, se puede participar en una conversación presencial mientras se intercambian mensajes de WhatsApp con otras personas o grupo, se consulta en otra pestaña el email que acaba de llegar para ver si es urgente o no y se tiene abierto Twitter por si salta una notificación relevante. Este comportamiento no es anómalo ni puede ser entendido como síntoma de un síndrome patológico de falta de atención. Por el contrario, formaría parte del 
entrenamiento en uno de los citados conocimientos prácticos necesarios para una adecuada alfabetización digital.

Otra habilidad indispensable señalada por la NCTE sería la de crear y analizar textos multimedia o hipertextos, algo a lo que ya están acostumbrados los usuarios avanzados del móvil. Desde el smartphone suben constantemente a las redes sociales textos, fotos, videos e incluso podcasts de sonido con los que construyen sus perfiles. Además lo hacen de manera selectiva, pensando el impacto que desean obtener, su adecuación a los gustos del entorno, su novedad y originalidad. Suelen ser conscientes de cuándo una foto precisa un pie de texto para orientar su interpretación en el sentido que ellos desean y demuestran una notable habilidad para jugar con la ambigüedad y la capacidad de evocación de las instantáneas. Buscan con esmero las respuestas aprobatorias y los "me gusta" de sus seguidores y círculos de amistades, además de participar como críticos (mostrando su aprobación o disgusto) de las aportaciones de otros. Manejan conjuntos complejos de reglas, con frecuencia no explícitas, que resultan difíciles de entender para los adultos no digitalizados. Estos, cuando intentan ponerse al día y construirse un perfil en alguna red social, echan en falta un manual escrito a la antigua usanza analógica. Se sorprenden de la facilidad con la que los más jóvenes interiorizan las reglas del mundo digital sin haber leído un manual, pero siguen considerando inadecuada como forma de aprendizaje la transmisión de conocimientos sin texto escrito e impreso, conseguida sobre la marcha, a través de las recomendaciones de otros o visionando demos y tutoriales en YouTube. Como señalan Green y Hannon (2007, pp. 20), los más jóvenes no parecen precisar de mucha orientación docente, sino que van explorando y adquiriendo confianza hasta que intuitivamente aprenden a manejar, como mínimo, los rudimentos básicos de cualquier programa o aplicación que despierta su interés. Aunque todo esto puede hacerse desde el ordenador, la inmediatez del móvil y la posibilidad de utilizarlo desde cualquier lugar, rodeados de compañeros conectados y con los que compartir experiencias e interacciones físicas al mismo tiempo que virtuales, suele tener más peso que la incomodidad del tamaño reducido de la pantalla de este dispositivo.

La necesidad de aprender y asumir las responsabilidades éticas de un entorno digital tan flexible y complejo, última habilidad citada por la NCTE, es aparentemente la más difícil de gestionar. Sin duda, esta dificultad estriba sobre todo en el hecho de que no existe una lista detallada de responsabilidades y códigos éticos generales acerca de cómo comportarse en cada caso. Bien es cierto que, en cada ámbito profesional, existen una serie de normas y preceptos éticos que, aunque no suelen estar escritos, están relativamente bien interiorizados por sus miembros. También lo es que la configuración del mundo digital obliga a adaptar y replantear esos códigos para adecuarlos a una realidad cambiante y que el proceso es lento y todavía pleno de vacíos por llenar. No obstante, en términos generales, el espacio digital tiene reglas y códigos de conducta que cualquier usuario ha de aprender y respetar, y aunque no suele existir una autoridad sancionadora, el control lo suele ejercer la comunidad virtual en las que se participa. Los usuarios avanzados del smartphone son 
conscientes de la existencia de esas reglas y códigos de conducta, de sus límites y de la importancia de respetarlas. Tienen una parte del camino aprendido, aunque a veces su impaciencia por explorar les lleve a cometer errores, a caer en excesos o a incumplirlas. Una vez más, el móvil puede resultar la herramienta ideal para iniciar el proceso de orientación e interiorización de códigos de conducta basados en principios éticos de carácter general y, sobre todo, a llevarlos a la práctica.

Como hemos podido ver, el móvil o smartphone es un dispositivo de uso generalizado que contribuye de manera directa a la adquisición de una serie de conocimientos prácticos que la NCTE valora como imprescindibles para una adecuada alfabetización digital que permita afrontar con éxito los retos de la vida cotidiana del siglo XXI. Unas competencias que no parecen estar disponibles en los proyectos e itinerarios curriculares habituales de la escuela actual y que, sin embargo, resultan fundamentales. Casi podríamos afirmar, tras lo aquí expuesto, que el smartphone está siendo el principal medio para que, sin intervención directa de la institución escolar, las generaciones futuras adquieran las competencias y desarrollen las actitudes necesarias para integrarse y moverse con soltura en la era digital. Una forma de adquisición de conocimiento que, curiosamente, parece cumplir muy bien las cualidades que se esperan de un entorno adecuado para el desarrollo del pensamiento digital. Se trata de un entorno descentralizado, flexible y sin reglas rígidas, entre pares, con incentivos para implicarse y disfrutar del aprendizaje, disponiendo de un potente dispositivo portable que abarca todas las aplicaciones multimedia más habituales. En gran medida el móvil está aportando tanto las herramientas como los conocimientos prácticos para la alfabetización digital que no es capaz de proporcionar la escuela actual. Curiosamente, como señala Seiter (citado en Ito 2010, pp. 298), las habilidades en el uso de tecnologías digitales se cultivan y adquieren fundamentalmente en el hogar y en entornos sociales informales, mientras que la escuela no juega un papel principal en la adquisición de capacidades relacionadas con las nuevas tecnologías.

Ha llegado el momento del pragmatismo, de modo que si no puedes con tu rival, únete a él. Eliminemos el móvil de la lista de enemigos e introduzcámoslo en la escuela pensándolo como un aliado, como un medio eficaz para construir conocimiento de manera cooperativa. Tiene que ser un proceso en el que el docente revise su papel tradicional y su posición de autoridad. Se aprende cooperando y explorando, más como "primus inter pares" que como guardián de las esencias. No basta con la curiosidad, es preciso moverse siempre pensando nuevas posibilidades, abriendo caminos, compartiendo, en comunidad. Quizá un buen ejercicio de partida sería intentar descartar el papel como elemento central de referencia. No se trata de eliminar o rechazar nada, sino de proponerse nuevas formas de pensar el aprendizaje y, para ello, puede resultar útil plantearse retos concretos que obliguen a cambiar las perspectivas habituales. Propongo por ello un salto hacia el hipertexto que implique a los alumnos en una tarea común de construcción de conocimiento. 
El móvil es una excelente herramienta para la búsqueda y acumulación de información. Ya no hace falta acarrear pesados diccionarios ni enciclopedias y, además, la obsolescencia es menor porque el proceso de actualización de los datos digitales es más fácil e inmediato. La ventaja añadida es que el formato de la información puede (y debe) ser multimedia, es decir, texto, fotos, video, podcasts, etc. Puesto que suele haber disponibles enormes cantidades de información sobre cualquier tema, una cuestión fundamental es desarrollar la capacidad de selección en términos de relevancia y adecuación a las metas perseguidas, de modo que se fomente la capacidad de "consumo crítico" o "detección de basura" (Rheingold o.c. , pp. 25). Esta es la manera de aprender a desechar lo irrelevante o accesorio y a reconocer lo significativo e importante en un mundo digital caracterizado por la dispersión de la información frente al texto impreso que se orienta a concentrarla y se construye y redacta con ese fin. Esta capacidad de discernimiento y selección está estrechamente asociada a la multitarea, pues implica también detectar y descartar lo accesorio y quedarse con lo esencial.

Toda la información localizada y valorada como relevante puede almacenarse en una carpeta en una "nube" donde podría haber otras subcarpetas establecidas con distintos fines, de modo que el docente pueda reconocer y luego calificar si fuera necesario, las aportaciones de cada individuo o grupo de trabajo. Así resulta fácil monitorizar el trabajo realizado e interactuar orientando y cooperando. La información, datos y contenidos se pueden modificar y actualizar en cualquier momento, se pueden controlar los cambios y realizar un proceso de tutorización en tiempo real si se desea. Así, una actividad que comienza en la clase puede quedar abierta para que los participantes añadan aportaciones en cualquier instante y desde cualquier lugar, rompiendo con la barrera mental de que el proceso de aprendizaje es sólo trabajo obligatorio y penoso que hay que realizar de manera preceptiva y exclusiva en el rígido horario lectivo. Esta apertura permite una manera diferente y más intensa de implicación del estudiante, que con su móvil en el bolsillo puede reaccionar ante cualquier estímulo, convertir su observación o inspiración momentánea en un dato y guardarlo en su aparato para elaborarlo más adelante o subirlo directamente a la nube donde se almacenan las aportaciones. La obligación se puede convertir con facilidad en juego exploratorio siempre abierto y con el que se puede conectar y desconectar para aprovechar los mejores momentos de inspiración porque el smartphone está siempre disponible.

Utilizar el móvil en el proceso de aprendizaje formal abre la posibilidad a un "estado de atención latente". Es decir, que sin pensar permanentemente en la tarea asignada, mantienen una alerta inconsciente para captar potenciales informaciones emergentes una vez se abandonan las aulas, ampliándose así el tiempo y el espacio de aprendizaje. La escuela sale de la escuela y se abre en el espacio y el tiempo. En realidad, esto no supone un gran cambio para unos alumnos que están habituados a relacionarse con su entorno a través del móvil, un móvil que, asociado también al aprendizaje escolar, acaba por integrar ese proceso en el conjunto de usos cotidianos, habituales e informales, en todo lugar y 
momento. A partir de esta conjunción integradora de usos, la separación entre tiempo y espacio escolar y extraescolar se hace más difusa y compleja. El aprendizaje monitorizado y flexible de la escuela se suma e integra con el autogestionado de navegación libre por los mares de información del ciberespacio (véase Lévy, o.c. , pp. 142). Cualquier vivencia, idea u observación forma parte de un flujo que se puede orientar y resignificar para asociarlo al proyecto escolar si se considera relevante, a la vez que con el ocio y el "tiempo libre". El uso habitual de la tecnología digital de la que disponen, muy especialmente la del smartphone, ha convertido a esos jóvenes usuarios en sofisticados observadores de su entorno. Un entorno que escanean con avidez y gran velocidad, que no piensan ni valoran principalmente en términos verbales o textuales y del que extraen datos multimedia que utilizan de maneras muy creativas y antes impensables. Unos datos multimedia que Eco (1981, pp. 286) consideraba con un nivel de complejidad mayor que el código verbal o escrito, al atribuir al audiovisual una tercera articulación propia y exclusiva, considerándolo un medio de comunicación más rico, capaz de desencadenar a la vez varias connotaciones.

\section{Díselo con fotos (digitales)}

Una de las aplicaciones más utilizadas del móvil es, sin duda, la cámara fotográfica. La calidad de las fotos que se pueden tomar con el móvil resulta cada vez más elevada y hasta los fotógrafos profesionales reconocen su versatilidad y confiesan usarla más frecuente de lo que se piensa. Quizá, una prueba de esta afirmación es la existencia de libros, como el de Rodrigo Rivas (2015), dedicado a la reflexión sobre el desarrollo de un uso profesional de la fotografía con smartphone. Desde el inicio de su obra insiste en que este aparato es la cámara que siempre llevamos encima, es muy versátil, permite compartir al instante y nunca llama la atención en ningún contexto porque todo el mundo está acostumbrado a su presencia. Yo añadiría también que estamos acostumbrados a sacar fotos con el móvil sobre cualquier cosa que nos llama la atención o que queremos guardar para el recuerdo. Me atrevería incluso a afirmar que la fotografía digital es probablemente la actividad que más se ha integrado en las mentes analógicas sin demasiados problemas. Conozco abuelas que adoptaron el móvil cuando descubrieron que podían llevar en él y ver con claridad en sus pantallas las fotos de sus nietos y nietas y han acabado aprendiendo a usar WhatsApp para intercambiar imágenes y mensajes con ellos; sobre todo imágenes.

¿Qué ventajas tiene integrar la fotografía digital en la escuela? Ya hemos visto que no supone problema de costes, ni económicos ni de adaptación, porque va inseparablemente asociada al móvil que todos los alumnos suelen portar, además de que también están muy acostumbrados a tomar fotos de casi todo y a intercalarlas en sus mensajes o a subirlas a las redes sociales para compartirlas. Más aún, con la práctica habitual, han desarrollado, sin pretenderlo, una notable capacidad de construir y extraer significados complejos mediante el uso de fotografías. Las fotos digitales tienen numerosas ventajas, puesto que ya no se 
imprimen sino que se almacenan en la memoria de los dispositivos y no es necesario llevarlas a cuestas, se visualizan en las pantallas de los mismos con la posibilidad de ampliarlas para ver los detalles y las copias ni pierden calidad ni están limitadas. Al permitir recoger información y reproducirla sin apenas limitaciones no se lastra el impulso explorador delestudiante movido por la curiosidad y propenso a acumular datos digitales. Tampoco hay temor, como antaño con la fotografía analógica, a hacer una mala toma porque además del apoyo generoso de los automatismos, la posibilidad de visualizar de inmediato los resultados nos permite volver a capturar aquello que nos interesa. $\mathrm{Y}$ a hacerlo también desde muy diversos ángulos, para reducir cualquier posible pérdida de información por falta de perspectiva. Una fotografía no es sino el resultado de la mirada de quien maneja la cámara, y la fotografía digital nos permite recoger y acumular múltiples miradas de manera sencilla, rápida y contrastada, comprobando el resultado de nuestra recolección sobre la marcha. Al tomar la foto estamos guardando en la memoria de nuestra cámara representaciones de significados complejos. Miramos el visor, disparamos y acumulamos en un instante un buen número de representaciones visuales significativas. Según optemos por un tipo de encuadre u otro obtendremos perspectivas en las que incluiremos mayor número de datos sobre el contexto o más detalle sobre el objeto central de nuestra mirada. Sin embargo, la sencillez del proceso no tiene relación directa con la cantidad, calidad y densidad de información y significados que puede contener una instantánea si se sabe analizar en su contexto.

Por tanto, una fotografía puede proporcionar datos muy abundantes, pormenorizados y relativamente bien contextualizados en poco tiempo y de manera sencilla y eficaz. Imaginemos por un momento que necesitamos describir con detalle algo que estamos observando. Si decidimos tomar notas en un cuaderno o con un teclado, precisaremos de un periodo de tiempo prolongado. Más prolongado cuanto más detallada queramos que sea la descripción y es probable que siempre se pierda algún elemento contextual al que al anotar no le hemos dado mucha importancia. Con una serie de fotos, incluyendo diversos encuadres y perspectivas, podemos hacer lo mismo de manera más completa y en menos tiempo. Luego, cuando recuperemos las imágenes para una observación y análisis más minucioso, dispondremos de un material muy rico en detalles. No sólo eso, la fotografía digital permite ampliaciones, retoques, recortes, añadidos, y montajes de series que pueden añadir niveles de complejidad inusitados en los procesos de análisis y presentación de resultados (Lisón, 2005, pp. 18-19). La edición digital es una poderosa herramienta de gran ayuda para presentar mejor los hechos, hacerlos más comprensibles, acompañarlos de información añadida; facilita integrarlos de manera más completa en su contexto y no perder la perspectiva del entorno que los dota de un significado específico y particular. Todo ello se puede hacer ya desde el móvil.

Puesto que una fotografía es el resultado de una mirada al mundo que nos rodea, suelen tomar más fotos las personas más observadoras, ya que miran constantemente su entorno. Buscan un encuadre que les transmita sensaciones y significados que les parecen 
importantes y que intentan expresar y representar a través de una instantánea. En esa imagen congelada tratan de parar el tiempo y condensar ideas complejas asociadas con valores, con el sentido de las cosas, con conceptos difíciles de captar, expresar e interiorizar de otro modo. Esto es lo que las culturas hacen constantemente; cada vez que es preciso hacer comprensible y asimilable para todo un grupo diverso de personas un concepto que precisa de un nivel elevado de abstracción, se recurre a los símbolos. Gracias a esas representaciones, casi siempre icónicas, podemos interiorizar, asimilar y compartir ideas, conceptos y valores culturales que de otro modo resultarían inabarcables para la mayoría. Tomar fotos no es un pasatiempo para diletantes y puede resultar una actividad muy provechosa en el proceso de desarrollo de una serie de habilidades relacionadas con la capacidad de observación, la construcción de representaciones simbólicas con diversos niveles de significación y con el pensamiento complejo.

En la Antropología audiovisual se han desarrollado algunas técnicas que pueden trasladarse al entorno escolar y resultar de utilidad en los procesos de aprendizaje. Una de las características de la instantánea fotográfica es su dosis de ambigüedad si no dispone de una buena contextualización (un pie de foto, por ejemplo) y su capacidad de evocación. Estas cualidades pueden aprovecharse de diversas maneras. Además de potenciar la observación suele contribuir a desarrollar las capacidades asociadas con la correcta descripción y argumentación verbal. Podemos empezar por pensar en un tema de trabajo aparentemente sencillo como la descripción de un espacio sobre el que se dispone de poca información y al que es difícil de acceder si no se pertenece al círculo más próximo de una persona: el ámbito doméstico. Les pedimos a los estudiantes que tomen una serie de fotos sobre ese espacio y que luego las ordenen en una secuencia de forma que den respuesta a una pregunta previamente enunciada al encargarles las instantáneas. Aquí se abren distintas posibilidades a la hora de hacer la pregunta a la que han de responder con una serie de instantáneas fotográficas. Ésta puede ser más específica (los espacios domésticos que más te gustan) o más ambigua (tu espacio doméstico), con lo que dejaremos mayor o menor libertad de elección a la hora de hacer las tomas. Todo depende del objetivo que nos marquemos. Esto se combina con el número total de fotos a presentar. Si reducimos el número obligamos a una selección previa que implica, quizá, descartar algunos espacios. Por el contrario, si solicitamos obligatoriamente la presentación de un número amplio de imágenes estamos forzando la redundancia; no queda otro remedio que repetir tomas desde distintos ángulos y perspectivas de algunos espacios. De nuevo se obliga a una selección, pero ahora el resultado es una abundancia de detalles. Finalmente, las instantáneas han de ordenarse, de manera que haya que mirarlas siguiendo la lógica de presentación establecida por quien las ha tomado. A partir de aquí basta con pedir al autor o autora que nos presente su secuencia para poner en evidencia que las fotos obligan a explicarse y a explicarlas. Toca, inevitablemente, recurrir al discurso verbal y a su lógica narrativa gracias a esas imágenes producidas con el móvil. La abundancia o la escasez de detalles derivadas del distinto número de fotografías impulsa a complementarlas con un 
discurso sobre los significados centrales que se desean comunicar, sobre la forma elegida de representarlos y sobre otros elementos relevantes; incluso sobre lo que ha quedado fuera del encuadre. La lectura e interpretación de cualquier foto es un proceso complejo que precisa la confluencia de múltiples elementos contextualizadores que le otorgan sentido más allá de lo representado (Scherer, 1992, pp. 32). Sirva todo esto de ejemplo sobre las muchas posibilidades para aprovechar la fotografía digital en los procesos de aprendizaje; incluso puede servir para indagar sobre otros aspectos relacionados con la forma de actuar y organizar su mundo social por parte de los alumnos que habitualmente quedan fuera del conocimiento de los docentes.

Pretender agotar aquí la lista de posibilidades que abre la integración del smartphone y la fotografía digital en el proceso de aprendizaje formal, haciéndolo parte fundamental de una cultura escolar digital, sería tan ingenuo como pretencioso. No obstante, no podemos perder de vista que la adquisición de los conocimientos prácticos asociados a una alfabetización digital no se realiza principalmente en la escuela, sino en otros entornos y con herramientas, como el móvil, excluidas del entorno escolar. Más aún, en el entorno del aprendizaje institucionalizado todavía prevalecen principios de organización, pensamiento y autoridad propios de la era analógica que frenan la introducción y desarrollo de una cultura escolar digital. Mi propuesta de aprovechar herramientas y prácticas sociales y culturales ya existentes para avanzar en el proceso de digitalización de la escuela, intentando reducir las fricciones propias de cualquier proceso de cambio, se enfrenta a obstáculos importantes, algunos tan complejos como la persistencia de valores firmemente arraigados y propios de un modelo analógico. Frente a estas resistencias esperables cabe cambiar la perspectiva con la que miramos aquello que forma parte de nuestra cotidianidad. No podemos dar por sentado que la manera establecida de pensar, entender y hacer las cosas es la única o la mejor posible. Un enfoque alternativo, por leve y sutil que sea, puede abrirnos puertas hacia posibilidades insospechadas sobre cómo abordar y resolver problemas y situaciones que por habituales quedan desatendidas.

\section{Referencias bibliográficas}

Aguaded Gómez, J. I., y Tirado Morueta, M. (2008). Los centros TIC y sus repercusiones didácticas en primaria y secundaria en Andalucía. Educar, 41, 61-90.

Area, M. y Sanabria, A. L. (2014). Opiniones, expectativas y valoraciones del profesorado participante en el Programa Escuela 2.0 en España. Educar, 50(1), 15-39.

Barrantes, K., y Baron G-L. (2011). Análisis de la aplicación de algunos proyectos nacionales con el uso de nuevas tecnologías. El caso de nueve instituciones de educación de base en México y Colombia. Educar, 47(2), 365-378.

Barthes, R. (1981). Camera Lucida. Reflections on Photography. New York: Hill \& Wang. Castells, M. (2000). La era de la información. Vol. 1. La sociedad red. Madrid: Alianza. 
Cernea, M. (Coord.). (1995). Primero la gente. Variables sociológicas en el desarrollo rural. México: F.C.E.

Chagnon, N. A. (1968). Yanomamo: The Fierce People. New York: Holt, Rinehart \& Winston. Clastres, P. (1981). Investigaciones en antropología política. Barcelona: Gedisa.

Dussel, I. (2011). Aprender y enseñar en la cultura digital. Buenos Aires: VII Foro Latinoamericano de educación. Fundación Santillana.

Dussel, I., y Quevedo, L. A. (2010). Educación y nuevas tecnologías: Los desafíos pedagógicos ante el mundo digital. Buenos Aires: VI Foro Latinoamericano de educación. Fundación Santillana.

Eco, H. (1981). La estructura ausente: Introducción a la semiótica. Barcelona: Lumen.

Fortes, M., y Evans-Pritchard, E. E. (1979). Sistema políticos africanos. En J. R. Llobera (comp.), Antropología Política (pp. 85-105). Barcelona: Anagrama.

Fletcher, D. (2006). Technology integration: Do they or don't they? A self-report survey from PreK through 5th grade professional educators. AACE Journal, 14 (3), 207-219.

García Vallinas, E. (2011). Las culturas audiovisuales de niños y adolescentes, ajenas a la escuela. En A. Bautista, y H. Velasco (coords.), Antropología audiovisual: medios e investigación en educación (pp. 251-264). Madrid: Ed. Trotta.

García-Pérez, F. F. (2000). Un modelo didáctico alternativo para transformar la educación: el modelo de investigación en la escuela. Scripta Nova: Revista Electrónica de Geografía y Ciencias Sociales, 4, 55-78.

Gee, J. P. (2004). Learning by design: Games as learning machines. Interactive Educational Multimedia, 8, 15-23.

Gee, J. P. (2008). Learning and Games. En K. Salen (ed.), The Ecology of Games: Connecting Youth, Games, and Learning (pp. 21-40). Cambridge, MA.: The MIT Press.

Gee, J. P. (2010). A Situated Sociocultural Approach to Literacy and Technology. En E. A. Baker (ed.), The New Literacies: Multiple Perspectives on Research and Practice (pp. 165-193). New York : The Guilford Press.

Giordan, A. (1995). Los nuevos modelos de aprendizaje: ¿Más allá del constructivismo? Perspectivas, XXV (1), 107-124.

Gonzáles Alcantud, J. A. (1999). La fotoantropología, el registro gráfico y sus sombras teóricas. Revista de Antropología Social, 8, 37-55.

Gonzáles-Peiteado, M. (2013). Los estilos de enseñanza y aprendizaje como soporte de la actividad docente. Revista Estilos de Aprendizaje, 11(11), 51-70.

Green, H., y Hannon, C, (2007). Young People Are Spending Their Time in a Space that Adults Find Difficult to Supervise or Understand... London: Demos.

Ito, M. (2010). Work. En AA. VV. Hanging Out, Messing Around, and Geeking Out. Kids Living and Learning with New Media . Cambridge. MA.: MIT Press, 295-337.

Johnson, S. (2005). Everything Bad Is Good for You. New York: Riverhead Books.

Joyce, B.; Weil, M., y Calhoum, E. (2002). Modelos de Enseñanza. Barcelona: Gedisa 
Kotrlick, J.W., y Redmann, D. H. (2005). Extent of Technology Integration in Instruction by Adult Basic Education Teachers. Adult Education Quarterly, 55(3), 200-219.

Kottak, C. P. (1995). Cuando no se da prioridad a la gente: algunas lecciones sociológicas de proyectos terminados. En M. Cernea, (coord.), Primero la gente. Variables sociológicas en el desarrollo rural (pp. 493-531). México: F.C.E.

Lankshear, C., y Knobel, M. (2011). New Literacies Everyday Practices and Social Learning (Third Edition). London: Open University Press/ McGraw-Hill Ed.

Lee, R. B. (1979). The ;Kung San: Men, Women and Work in a Foraging Society. New York: Cambridge University Press.

Lévy, P. (2007). Cibercultura. La cultura de la sociedad digital. Barcelona: Anthropos.

Leyden, A. (2015). 40 Uses for Smartphones in school. https://www.examtime.com/blog/40-uses-for-smartphones-in-school/ (acceso, 1 de mayo 2016).

Lisón Arcal, J.C. (2011). Cliconocimientos. Construyendo el saber con un clic. En A. Bautista, y H. Velasco (coords.), Antropología audiovisual: medios e investigación en educación (pp. 35-52). Madrid: Ed. Trotta,.

Lisón Arcal, J. C. (2005). Investigando con fotografía en Antropología social. En C. Ortiz, C. Sánchez-Carretero, y A. Cea (coords.), Maneras de mirar. Lecturas antropológicas de la fotografía (pp. 15-30). Madrid: CSIC.

Lowie, R. H. (1979). Algunos aspectos de la organización política de los aborígenes americanos. En J. R. Llobera (comp.), Antropología Política (pp. 107-132). Barcelona: Anagrama.

Monereo, C. (2001). Ser estratégico y autónomo aprendiendo. Unidades didácticas de enseñanza estratégica. Barcelona: Graó.

Morin, E. (1994). Cultura y conocimiento. En P. Watzlawick, y P. Krieg (comps.), El ojo del observador (pp. 73-81). Barcelona: Gedisa.

Paredes Labra, J. (2011). Cambiar el panorama de las escuelas. En A. Bautista, y H. Velasco (coords.), Antropología audiovisual: medios e investigación en educación (pp. 152173). Madrid: Ed. Trotta.

Pospisil, L. (1963). The Kapauku Papuans of West New Guinea. New York: Holt, Rinehart \& Winston.

Rabbitt, P., Banerji, N., y Szymanski, A. (1989). Space Fortress as an IQ Test? Predictions of Learning and of Practised Performance in a Complex Interactive Video-Game. Acta Psychologica, 71 (1989), 243-257.

Rivas, R. (2015). La fotografía móvil. Madrid: Anaya Multimedia.

Rodríguez Rodríguez, J. C. (1999). Hipertexto. ¿Un Nuevo estilo de discurso antropológico? Revista de Antropología Social, 8, 109-119.

Rozak, T. (2006). El culto a la información. Barcelona: Gedisa.

Silberbauer, G. (1983). Cazadores del desierto. Cazadores y hábitat en el desierto de Kalahari. Barcelona: Mitre. 
Sancho, J. M., y Hernández, F. (2004). ¿Por qué no ha fructificado la propuesta del profesor como investigador? Y algunas propuestas para resistir a un presente nostálgico. Educar, 34, 39-51.

Sartori, G. (1998). Homo videns. La sociedad teledirigida. Madrid: Taurus.

Scherer, J. C. (1992). The Photographic Document: Photographs as Primary Data in Anthropological Enquiry. En E. Edwards, (ed.), Anthropology and Photography 18601920 (pp. 32-41). New Haven \& London: Yale University Press.

Velasco Maillo, H. (2011). Fotografías escolares, imágenes institucionales. En A. Bautista, y H. Velasco (coords.), Antropología audiovisual: medios e investigación en educación (pp. 15-34). Madrid: Ed. Trotta. 